\title{
Class II Reservoir Polymer Injection Parameters Impact on the Oil Dis- placement Efficiency
}

\author{
Wenchi Qu* Kaoping Song and Jicheng Zhang
}

Petroleum Engineering Institute of Northeast Petroleum University, Daqing, P.R. China

\begin{abstract}
In this study, we analyzed the characteristics of the class II reservoirs and the application of the polymer flooding in Daqing oil field, and also discussed the effects of polymer flooding parameters on reservoir properties and displacement results by numerical simulation. Based on the conceptual model of sandstone reservoirs, we studied the effects of the concentration, viscosity, relative molecular mass of polymer, and the injection rate on the recovery of polymer flooding by single factor analysis. We found that the variation of these factors had obviously effects on the results of polymer flooding to a certain limit. In the process of discussion, we treated the parameters of polymer by linear regression to analyze the results of polymer flooding, which can provide some guidance for reservoir development.
\end{abstract}

Keywords: Class II reservoir, Polymer, Numerical simulation, Development, Rheological characteristic.

\section{INTRODUCTION}

During the polymer flooding, the tracking and adjustment of polymer flooding schemes, the selection of operated wells and layers, and the optimization of injection parameters for polymer flooding are usually finished by the field engineers according to their experience [1-3]. The numerical simulation technology provides a more accurate approach to predict the displacement efficiency and dynamics of polymer flooding, which established the foundation to produce the remaining oil by polymer flooding [4-6].

\section{THE ESTABLISHMENT OF MODEL}

We build up a conceptual model based on the five-spot well pattern. This conceptual model includes 16 injection wells and 9 production wells, and the injector-producer distance is $250 \mathrm{~m}$. In the planar direction, the model consists of 3600 grid blocks and the grid step length is $10 \mathrm{~m}$. The permeability of conceptual model is $500 \mathrm{md}$. In the vertical direction, i.e. $\mathrm{Z}$ axis direction, the model only consists of one layer and the grid step length is $2 \mathrm{~m}$. We densified the grids near the central well in both planar and vertical direction to describe the velocity and viscosity field accurately, because the velocity of displacement fluid becomes larger around the downhole and smaller in the areas between the injection wells and production wells in the process of displacement [7]. Fig. (1) shows the five-spot well pattern and Fig. (2a) shows the conceptual model.

\section{PARAMETERS OF THE POLYMER}

We treated the relative permeability curves, rheological characteristic curves and adsorption curves by regression process, due to the parameters used in the calculation should be the parameters of polymer solution under the formation

*Address correspondence to this author the Petroleum Engineering Institute of Northeast Petroleum University, Daqing, P.R. China; Tel: 13936719188; E-mail: ziqiangbuxiaaa@163.com condition $[8,9]$. In addition, we modified the parameters of laboratory tests with the field test practice of polymer flooding.

Adsorption quantity of polymer: As the adsorption quantity increases, the radius of pore throat decreases, which increases the resistance of removing the oil film and decreases the mobility of displacement fluid. Therefore, The displacement efficiency is determined by the adsorption quantity of polymer.

Relationship between polymer viscosity and concentration: The viscoelasticity of polymer solution can improve the oil-water mobility ratio, prevent the break though of injected water, and expand the macro sweep volume. The viscosity of polymer solution is a function of polymer concentration and mineralization degree when the shear rate is 0 . In this study, we measured the viscosity versus concentration curves of different relative molecular weight polymers. The relative molecular weight of these polymers are $1200 \times 10^{4}$, $1900 \times 10^{4}, 2500 \times 10^{4}$ and $3200 \times 10^{4}$, respectively. The measured curves are shown in Fig. (2b).

Rheological characteristics: The polymer is the Newtonian fluid and its solution has the rheological characteristics, which means the viscosity of polymer is determined by the viscosity rate [10]. In this study, we measured the rheological curves by the DVIII rheometer and set up the following relationship between the viscosity and shear rate based on the power-law fluid model. The relationship is shown as below:

$$
\begin{aligned}
& \mu=K \cdot \gamma^{n-1} \\
& \gamma=\left(\frac{3 n+1}{4 n}\right)^{\frac{n}{n-1}} \cdot \frac{10000 \cdot V}{\sqrt{0.5 \cdot C \cdot k_{\mathrm{w}} \cdot \Phi}}
\end{aligned}
$$

$\mu$ is the apparent viscosity;

$\gamma$ is the shear rate; $\mathrm{n}$ is power-law index; 

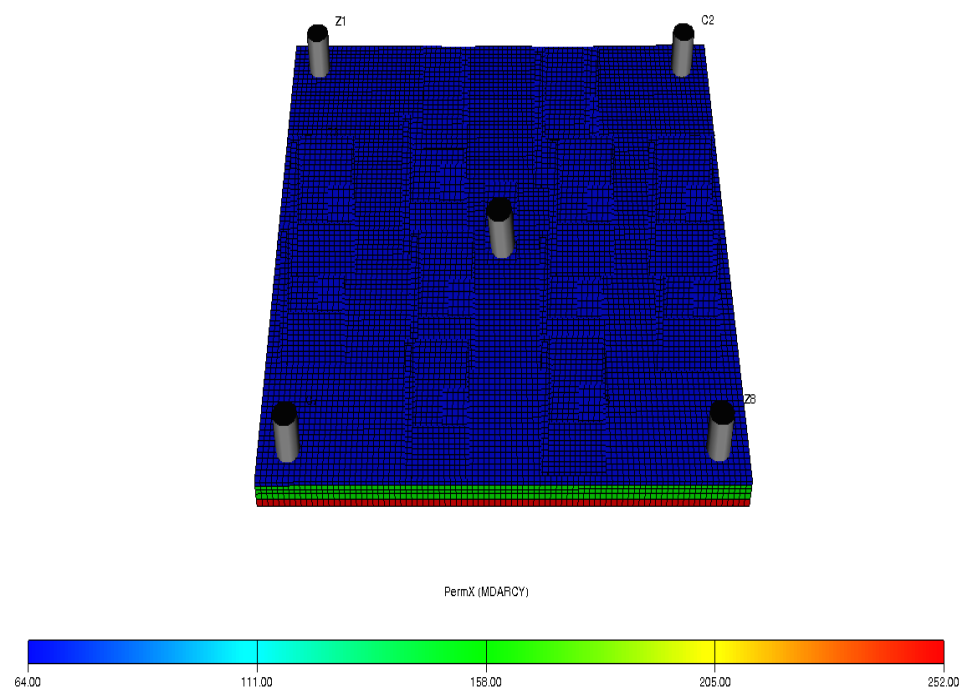

Fig. (1). The schematic of five-spot well pattern.

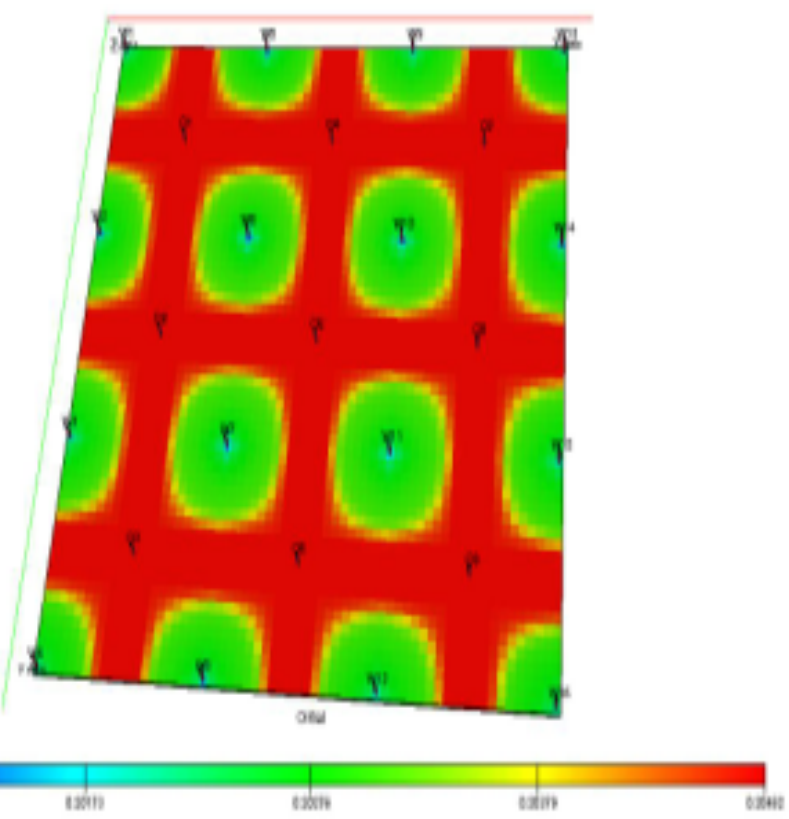

Fig. (2a). The schematic of conceptual model.

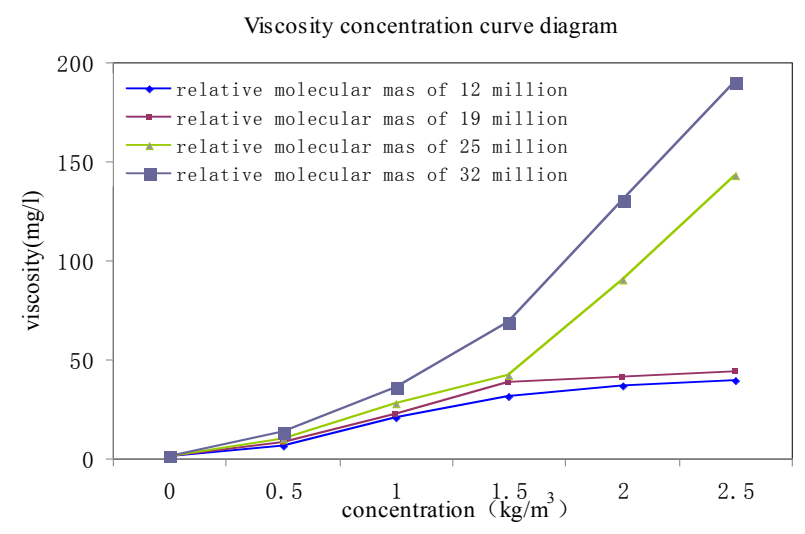

Fig. (2b). The viscosity versus concentration curves of different molecular weight polymers. $k_{w}$ is the permeability of cores measured with water;

$\Phi$ is the rock porosity;

$\mathrm{C}$ is a constant related to the pore shape.

The shear rate of polymer solution is closely related to the viscosity of polymer solution, while the velocity used in the polymer displacement is the seepage velocity. Therefore, we should convert the seepage velocity into the corresponding shear rate.

\section{INJECTION PARAMETERS ANALYSIS}

\section{Simulation schemes}

We simulated the entire development process of the class II reservoir with the conceptual model. Firstly, the water flooding is done until the water cut of the production well is 
Table 1. The relationship between recovery and relative molecular mass of polymers.

\begin{tabular}{|c|c|c|c|c|}
\hline Scheme & Relative Molecular Mass $\left(\mathbf{\times 1 \mathbf { 1 0 } ^ { \mathbf { 4 } } )}\right.$ & Recovery of Water Flooding (\%) & Recovery of Polymer Flooding (\%) & Enhanced Recovery (\%) \\
\hline \hline 1 & 1200 & 46.53 & 57.55 & 11.02 \\
\hline 2 & 1900 & 46.53 & 60.15 & 13.62 \\
\hline 3 & 2500 & 46.53 & 62.04 & 15.51 \\
\hline 4 & 3200 & 46.53 & 60.49 & 13.96 \\
\hline
\end{tabular}

Table 2. The relationship between recovery and polymer concentration.

\begin{tabular}{|c|c|c|c|c|}
\hline Scheme & Polymer Concentration (mg/L ) & Recovery of Water Flooding (\%) & Recovery of Polymer Flooding (\%) & Enhanced Recovery (\%) \\
\hline \hline 5 & 1000 & 46.53 & 57.39 & 10.86 \\
\hline 6 & 2500 & 46.53 & 59.55 & 13.02 \\
\hline 7 & 3500 & 46.53 & 57.83 & 11.3 \\
\hline
\end{tabular}

$98 \%$, then the polymer flooding is carried out with the polymer solution of different concentrations until the injection volume is $0.3 \mathrm{PV}$. Then continue water flooding until the water cut of the production well is $98 \%$ again. We did the single factor analysis to study the effects of each parameter on the recovery of polymer flooding (Figs. $3 \& 4$ ).

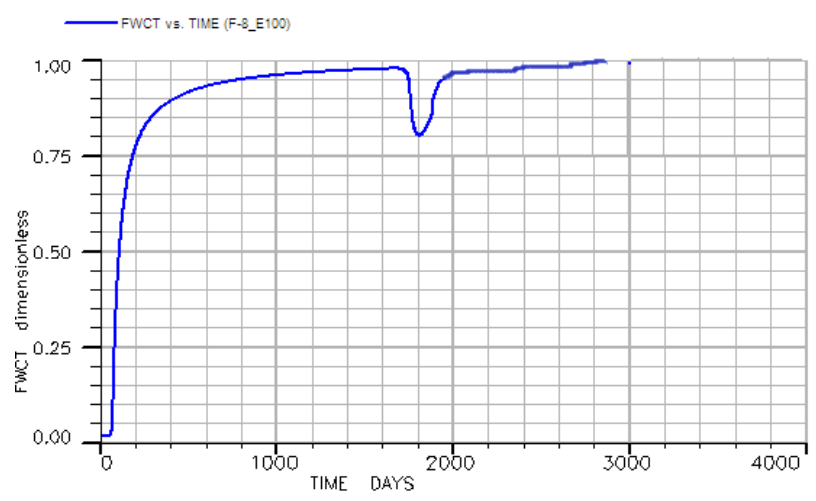

Fig. (3). The water cut of basic scheme.

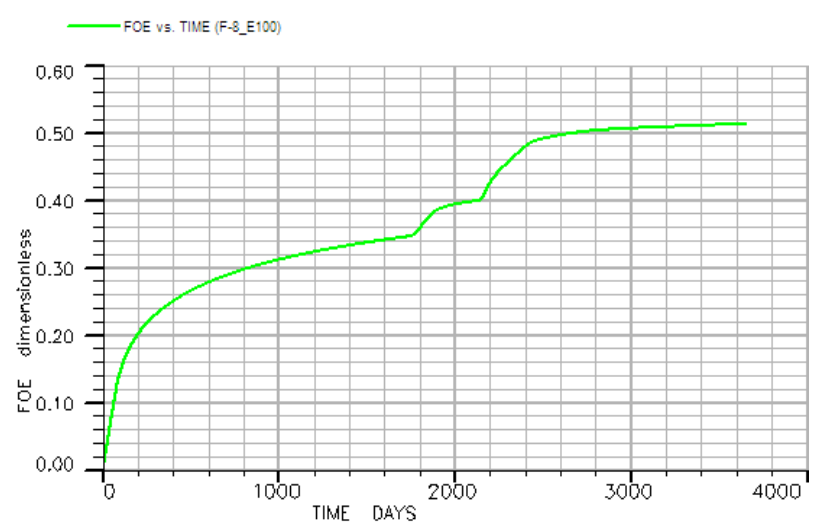

Fig. (4). Recovery of basic scheme.

\subsection{Relative Molecular Mass of Polymer}

In the schemes 1 to 4 , mineralization degree of the formation water is $6778 \mathrm{mg} / \mathrm{L}$, the polymer is polyacrylamide, and the solution concentration is $2000 \mathrm{mg} / \mathrm{L}$. The polymer flooding is carried out with the different polymers which are injected at a constant speed. The relative molecular mass of these polymers are $1200 \times 10^{4}, 1900 \times 10^{4}, 2500 \times 10^{4}$ and $3200 \times 10^{4}$, respectively. The relationship between recovery and relative molecular mass of polymers is shown in Table 1.

As shown in Table 1, the enhanced recovery of scheme 3 is higher than schemes 2 and 4, while the polymer relative molecular mass of scheme 3 is bigger than scheme 2 but smaller than scheme 4 . The polymer flooding recovery of $2500 \times 10^{4}$ is higher than $1900 \times 10^{4}$ for $1.89 \%$. Therefore, to a certain limit, the recovery of polymer flooding increases with the increase of the polymer relative molecular mass. This is because higher relative molecular mass may increase the tackifier effect of the solution and the amount of the polymer retention, which results in higher residual resistance factor and expands the swept volume. However, when relative molecular mass of the polymer exceeds the certain limit, the radius of molecular is larger than the pore radius [11, 12]. Big polymer molecular may block the formation and the injected pressure may be increased, which will decrease the swept volume of the polymer flooding.

\subsection{Concentration of Polymer Solution}

In the schemes 5 to 7 , mineralization degree of the formation water is $6778 \mathrm{mg} / \mathrm{L}$, and the relative molecular mass of the polymer is $1900 \times 10^{4}$. The polymer concentration in schemes $5,6,7$ is $1000 \mathrm{mg} / \mathrm{L}, 2500 \mathrm{mg} / \mathrm{L}$ and $3500 \mathrm{mg} / \mathrm{L}$, respectively. We studied the effects of the polymer concentration on the development efficiency by the above conceptual model. The relationship between recovery and polymer concentration is shown in Table 2 . 
Table 3. The displacement results of schemes 8 to 11 .

\begin{tabular}{|c|c|c|c|c|}
\hline Scheme & Polymer Concentration (mg/L) & Recovery of Water Flooding (\%) & Viscosity(mPa·s) & Recovery of Polymer Flooding (\%) \\
\hline \hline 8 & 1200 & 3500 & 41.66 & 60.26 \\
\hline 9 & 1900 & 2500 & 42.03 & 61.31 \\
\hline 10 & 2500 & 1500 & 41.95 & 60.95 \\
\hline 11 & 3200 & 1100 & 40.63 & 59.62 \\
\hline
\end{tabular}

Table 4. The results of schemes 12 to 16 .

\begin{tabular}{|c|c|c|c|c|}
\hline Scheme & Injection Rate (pv/a) & Recovery of Water Flooding (\%) & Recovery of Polymer Flooding (\%) & Enhanced Recovery (\%) \\
\hline \hline 12 & 0.1 & 46.53 & 57.66 & 11.13 \\
\hline 13 & 0.2 & 46.53 & 58.55 & 12.02 \\
\hline 14 & 0.3 & 46.53 & 59.38 & 12.85 \\
\hline 15 & 0.4 & 46.53 & 58.68 & 12.15 \\
\hline 16 & 0.5 & 46.53 & 57.62 & 11.09 \\
\hline
\end{tabular}

As shown in Table 2, the enhanced recovery of scheme 6 is higher than schemes 5 and 7 , while the polymer concentration of scheme 6 is bigger than scheme 5 but smaller than scheme 7. The polymer flooding recovery of $2500 \mathrm{mg} / 1$ is higher than $1000 \mathrm{mg} / 1$ by $2.16 \%$. We know through Fig. (2) that the viscosity of polymer is influenced by the concentration. Therefore, to a certain limit, the recovery of polymer flooding increases with the increase of the polymer concentration. This is because a higher concentration may increase the amount of polymer molecular per unit volume. However, when the concentration of the polymer exceeds the certain limit, the viscosity of polymer solution increases obviously [13]. The polymer molecular is difficult to pass through the pore and throat, which will decrease the displacement efficiency of the polymer flooding.

With the Compatibility study of formation, we found that the block effect caused by the polymer, which has too high concentration, would reduce the swept volume and the recovery of polymer flooding in Class II reservoirs.

\subsection{Viscosity of the Polymer Solution}

Table 3 shows the displacement results of schemes 8 to 11. The polymer in these schemes has different relative molecular mass, so we adjusted the polymer concentration to make the viscosity of these solutions be approximately the same. The displacement results show that the recovery of these schemes with different polymers, which has different relative molecular mass, is approximately the same.

\subsection{Injection Rate}

In the schemes 12 to 16 , the relative molecular mass of the polymer is $1900 \times 10^{4}$, and the solution concentration is $2000 \mathrm{mg} / \mathrm{L}$. The injection rate in the schemes 12 to 16 is set to $\mathrm{be} 0.1 \mathrm{pv} / \mathrm{a}, 0.2 \mathrm{pv} / \mathrm{a}, 0.3 \mathrm{pv} / \mathrm{a}, 0.4 \mathrm{pv} / \mathrm{a}, 0.5 \mathrm{pv} / \mathrm{a}$, respectively. We studied the effects of injection rate on the devel- opment efficiency by the above conceptual model. The results of schemes 12 to 16 are shown in Table 4 .

As shown in Table 4, the enhanced recovery increases with the improvement of the injection rate when the injection rate is smaller than $0.3 \mathrm{pv} / \mathrm{a}$, which is opposite when the injection rate is more than $0.3 \mathrm{pv} / \mathrm{a}$. Therefore, to a certain limit, a higher injection rate can improve the recovery of polymer flooding $[14,15]$. However, when the injection rate is too high, the injection pressure would increase, and the large pore path and dominant flow channel is formed during the sandstone formation, which means the displacement fluid flow along the large pore path, can't be swept in the low permeability areas, thereby reducing the displacement efficiency.

\section{CONCLUSION}

We found out the adsorption characteristics, rheological characteristics, and the relationship between the polymer viscosity and the concentration of polymer solution for the polymer flooding in Class II reservoirs by analyzing the parameters of polymer flooding.

The results of numerical simulation show that to a certain limit, a higher relative molecular mass of the polymer may improve the displacement efficiency obviously. Higher concentration of the polymer can also increase the swept volume and increase the polymer flooding recovery.

For the polymers of different relative molecular mass, when the viscosity of their solutions is approximately the same, they have the same recovery of polymer flooding approximately.

\section{SUGGESTION}

In general, the polymer with large relative molecular mass and high concentration can enhance the oil recovery 
effectively. However, when the relative molecular mass is too large and the concentration of polymer solution is too high, the gyration radius of the polymer is bigger than the pore throat radius of the formation, which will cause high injection pressure and formation blockage, reducing the mobility of fluid, and increasing the difficulty of the field injection. In this study, when the relative molecular mass of polymer is $1900 \times 10^{4}$ and the concentration of polymer solution is $2500 \mathrm{mg} / \mathrm{L}$, the polymer solution has good compatibility with the formation pores under the condition of class II reservoirs, which effective permeability is $500 \mathrm{md}$. To a certain limit, the increase of the injection rate can enhance the recovery of polymer flooding. For the class $I I$ reservoirs in Daqing oil field, the suitable injection rate is $0.3 \mathrm{PV} / \mathrm{a}$.

\section{CONFLICT OF INTEREST}

The authors confirm that this article content has no conflict of interest.

\section{ACKNOWLEDGEMENT}

This paper belongs to the project of the "The new technology of improve the oil recovery late oilfield exploitation; National science and technology major special project" No.2011ZX 05009-004.

\section{REFERENCES}

Y.G Fu, and J. Qian, Monitoring and modification application of numerical simulation in polymer flooding, Journal of Chengdu University of Technology (Science \& Technology Edition). vol. 26, pp. 11-14, 2008.

[2] N. Jiang, and X.J. Wang, Realization and application of numerical simulation of high polymer flooding technology, Journal of Chengde Petroleum College, vol. 5, pp. 13-16, 2013.

[3] X.Y. Li, J. Hou, and Q. J. Du. Sensibility analysis of polymer flood parameters by using a novel potential predictive mathematical model. Oilfield Chemistry, vol. 10, pp. 163-167, 2005.
[4] H.B. Liu, Z.X. Zhou, and G.Z. Liao. High molecular weight polymer flooding effect factors analysis. Daqing Petroleum Geology and Development, vol. 21, pp. 48-51, 2002.

[5] K.W. Lu. Polymer flooding numerical simulation parameters estimation techniques and applications. Petroleum Geology and Engineering, vol. 27, pp. 116-117, 2013.

[6] Z.Q. Guo, M.Z. Dong, Z.X. Chen, and J. Yao. "Dominant scaling groups of polymer flooding for enhanced heavy oil recovery", Industrial and Engineering Chemistry Research, vol. 52, pp. 911-921, 2013.

[7] D.X. Liu, X.T. Zhao, W. Liang, and J.W. Li, The stability and breakage of oil-in-water from polymer flooding produced water, Petroleum Science and Technology, vol. 31, pp. 2082-2088, 2013.

[8] A. Samanta, A. Bera, K. Ojha, and A. Mandal, Comparative studies on enhanced oil recovery by alkali-surfactant and polymer flooding, Journal of Petroleum Exploration and Production Technology, vol. 2, pp. 67-74, 2012.

[9] Y. Fan, L.J. Durlofsky, and H. Tchelepi, "Numerical simulation of the in-situ upgrading of oil shale", SPE Reservoir Simulation Symposium Proceedings, vol. 1, pp. 477-493, 2009.

[10] S. Yaser, A. Mohammad, K Hassan, and T. Ole, "Experimental investigation and numerical simulation of steam flooding in heavy oil fractured reservoir", Society of Petroleum Engineers Western North American Regional Meeting 2011, pp. 333-343, 2011.

[11] Z.G. Fu, Z.P. Wang, and L.L. Shi, "Numerical simulation of the tiny-oil ignition burner in the coal fired boiler", Journal of Engineering Thermophysics, vol. 29, pp. 609-612, 2008.

[12] X. Zheng, Y. You, G.X Lin, N. Wan, and Y.X. Zhang, "Fluid-solid coupling seepage-based numerical simulation of mechanical oil expression from peanut", 2009 International Conference on Engineering Computation, pp.67-70, 2009.

[13] J.S. Zhao, T.T. Li, M. Zhang, and Z.M. Li, "Study the displacement characteristics of foam flooding after polymer flooding on NMR", Advanced Materials Research, vol. 361-363, pp. 493-498, 2012.

[14] W.H. Li, X.A. Wang, Z.K. Wang, and J.C. Liu, "Construction and practice for practical teaching base on campus for petroleum engineering", Applied Mechanics and Materials, vol. 121-126, pp. 740744, 2012.

[15] Q.H. Zha, "Growth and potential of oil in place and production in the Bohai Bay petroleum region", Shiyou Xuebao/Acta Petrolei Sinica, vol. 28, pp. 16-20, 2007.

Received: April 21, 2015

Revised: May 17, 2015

Accepted: June 01, 2015

(C) Daiyin et al.; Licensee Bentham Open.

This is an open access article licensed under the terms of the Creative Commons Attribution Non-Commercial License (http://creativecommons.org/licenses/by-nc/4.0/) which permits unrestricted, non-commercial use, distribution and reproduction in any medium, provided the work is properly cited. 